\title{
In Memoriam: Michael John Welch, Ph.D. 1939-2012
}

\author{
Timothy J. McCarthy, ${ }^{1}$ Henry F. VanBrocklin ${ }^{2}$ \\ ${ }^{1}$ Pfizer, Inc, Eastern Point Rd, MS8260-2605, Groton, CT, 6340, USA \\ ${ }^{2}$ University of California San Francisco, San Francisco, CA, USA
}

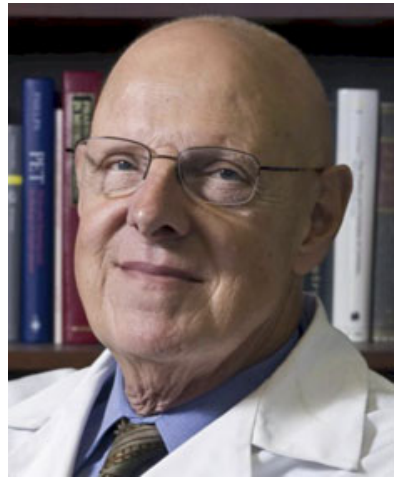

On May 6, 2012 the Molecular Imaging community lost one of the true pioneers of Radiopharmaceutical Chemistry, Michael J. Welch. Over his prestigious career, Mike's contributions to the field were enormous, and his legacy will live on in the world through the many investigators that he trained and collaborated with over the years.

Mike was born in Stoke on Trent on June 28, 1939. He attended school locally before winning an open scholarship to St. Catherine's College at the University of Cambridge to read Natural Sciences. After graduation in 1961, he went on to the University of London and obtained a Ph.D. in Chemistry in 1965 from Queen Mary College for his studies in recoil reactions of tritium. That year, he moved to the USA for postdoctoral studies at the Brookhaven National Laboratory with Al Wolf, Ph.D. to further pursue his interest in hot atom chemistry. In 1967, Mike moved to St Louis to accept a faculty position at Washington University working with Dr. Michel TerPogossian; at this point, he turned his attention toward medical applications of radiochemistry, including isotope production. Over the 45 years that Mike was at Washington University, he became internationally recognized for his contributions to radioisotope preparation, accelerator target chemistry, and radiopharmaceutical chemistry which are reflected in a total of 558 manuscripts, 4 books, and 73 contributed book chapters.

Correspondence to: Timothy McCarthy; e-mail: timothy.j.mccarthy@pfizer.com
Mike's contributions to the field went well beyond radiopharmaceutical chemistry, in addition to his exceptional intellect, one of his key skills was the ability to develop longstanding collaborations across a variety of disciplines. Many of these originated during the early days of his career at Washington University. His collaborative interactions gradually moved in wider, more global circles as people's careers took them to other institutions and organizations. One example of this collaborative effort is his work with John Katzenellenbogen, Ph.D. at the University of Illinois, on radiolabeled estrogens. Mike's willingness to collaborate outside of the chemistry arena allowed him to see many novel radiopharmaceuticals translate from the laboratory into the clinic.

Mike was also an early adopter and developer of technologies, and many people who have spent time working with him will remember the enthusiasm with which any new (or prototype) piece of equipment would be received. Through these interests, he was able to identify opportunities. Another important legacy from Mike was the development of cyclotron produced copper-64 and establishment of the NIH Research Resource to supply such isotopes. This advance, in combination with small animal imaging and even now human imaging, has proven to be very widely used as evidenced by many articles featured in this journal. Through the Research Resource, Mike made available several "new" imaging isotopes that were heretofore unavailable commercially, spawning a breadth of nuclear imaging research.

During his career, Mike's scientific contributions garnered numerous honors. He won all of the major awards from the Society of Nuclear Medicine, including the Charles de Hevesy Nuclear Medicine Pioneer award and the Benedict Cassen Prize, and he witnessed the creation of a new award named in his honor. His achievements were also recognized by the American Chemical Society, the American College of Radiology, the Radiological Society of North America, the Society of Molecular Imaging, and the Academy of Molecular Imaging. In 1999, he was elected as a member of the Institute of Medicine and worked on numerous advisory panels for the Institute and the National 
Academy of Sciences. He was one of the founding members of the International Symposium of Radiopharmaceutical Chemistry, the Workshop on Targetry and Target Chemistry and served as the first President of the Society of Radiopharmaceutical Sciences, founded from the biannual symposia. He also served as the President of the Society of Nuclear Medicine from 1984 to 1985.

Outside of his academic career, Mike remained very competitive. In his youth, he enjoyed swimming and played water polo at Cambridge. He was a lifelong fan of Stoke City football (soccer) and reveled in their promotion to the Premier League. Another passion of Mike was raising and competitively showing Norwegian Elk Hounds.

Family was a very important part of his life, and he was always sympathetic to the challenges of work/life balance that we all face in our everyday lives. Mike is survived by his two children, Colin Welch of New Canaan and Lesley Tomlin of St. Louis; and five grandchildren, Colin, Jr., Payton, Ava, Devin, and Celia. He will be dearly missed by his longtime companion, Mary ("Mickey") Clarke of St. Louis. Above all else, and to the many of us who knew him, Mike will be remembered as both a mentor and friend. Over the years, Mike built a strong team that was supported by many technologists and staff scientists who came into the field and were trained in all aspects of radiopharmaceutical chemistry and molecular imaging. Throughout his tenure at Washington University, scientists from all over the world spent time in his laboratory. Mike mentored more than 20 students earning Ph.D.s, in addition to many more postdocs and visiting scientists who were trained at Washington University before embarking on their own careers. He inspired us in many ways, especially by reminding us that we are trained as scientists and that this basic grounding provides a springboard for us to continually learn. Many of the radiopharmaceutical chemistry laboratories throughout the world have at their core someone with a connection to Mike and his legacy.

To honor Mike and his scientific legacy, a foundation has been established in his name to support research in nuclear medicine and radiopharmaceutical chemistry. Memorial contributions may be made to The Dr. Michael J. Welch Foundation, 55 Walls Drive, Fairfield, CT, 06824 USA or visit www.mjwelchfoundation.org. 